\title{
Tick Size Change and Liquidity Provision on the Tokyo Stock Exchange
}

\author{
Hee-Joon Ahn \\ College of Economics and Commerce \\ Sookmyung Women's University \\ Seoul, Korea \\ Jun Cai \\ Department of Economics and Finance \\ City University of Hong Kong \\ Hong Kong, China \\ Kalok Chan \\ Department of Finance \\ Hong Kong University of Science \& Technology \\ Hong Kong, China \\ Yasushi Hamao \\ Department of Finance and Business Economics \\ Marshall School of Business \\ University of Southern California \\ Los Angeles, U.S.A.
}

October 2001

Key words: Tick size change, quoted spread, effective spreads, trading volume, monopoly rent

JEL classification: C14; G15

We would like to thank the City University of Hong Kong for providing various types of support.

Financial support from RGC Competitive Earmarked Research Grants 1998-2000 and 1999-2001 (Cai) is gratefully acknowledged. Caroline Biebuyck provided the editorial assistance. 


\title{
Tick Size Change and Liquidity Provision on the Tokyo Stock Exchange
}

\begin{abstract}
The Tokyo Stock Exchange (TSE) introduced a change in its minimum tick sizes on April 13, 1998, for stocks traded at certain price ranges. We investigate the liquidity and market quality of the stocks affected by the tick size change, using a unique and comprehensive tick-by-tick data. We find that the quoted spread (effective spread) declined significantly by 20 to 50 percent (by 24 to 60 percent) after the tick size change. Reductions in spread are greater for firms with greater tick size reductions, greater trading activity, and higher monopoly rent proportion in the bid-ask spread component. Although investors are more aggressive in posting quotes, there is no definite evidence of an increase in trading volume. Overall, our evidence is consistent with the hypothesis that price competition in the limit order book increased substantially after the tick size change.
\end{abstract}




\section{Introduction}

In recent years, many stock exchanges around the world have adopted smaller tick sizes in an effort to reduce transactions costs and increase trading volume. The American Stock Exchange (AMEX) first reduced the minimum price increment from $\$ 1 / 8$ to $\$ 1 / 16$ for stocks priced between $\$ 1$ and $\$ 5$ in September 1992, and then for stocks between $\$ 5$ and $\$ 10$ in February 1995. In May 1997, the change was applied to all stocks. The Toronto Stock Exchange reduced its minimum tick from $\mathrm{C} \$ 0.125$ to C\$0.05 for stocks traded at or above C\$5 in April 1996. The New York Stock Exchange and NASDAQ switched to $\$ 1 / 16$ pricing shortly after the Common Cents Pricing Act was introduced in the U.S. Congress in March 1997, and 1 cent (decimalization) in January 2001.

This has spurred a lot of interest on the effects of minimum price variation on the spread, depth, and liquidity. Previous studies typically investigate two issues. The first set of studies compares the market quality before and after the reduction of minimum price variation in various markets, including the American Stock Exchange, Toronto Stock Exchange, New York Stock Exchange, Stockholm Stock Exchange, Singapore Stock Exchange, and Australian Stock Exchange. Harris (1997) provides an excellent review of evidence in different markets. ${ }^{1}$ The second set compares the impact of endogenous tick size changes for different stocks as a result of stock price passing through different threshold levels. Examples of these studies include Harris (1996) on the Paris Bourse and NASDAQ, Bessembinder (1998) on NASDAQ, and Chan and Hwang (2001)) on the Stock Exchange of Hong Kong. ${ }^{2}$

In this paper, we examine the change of the minimum tick size in the Tokyo Stock Exchange during 1998. Table 1 summarizes the tick sizes for different price ranges before and after the change. The primary difference between U.S. stock exchanges and the Tokyo Stock Exchange is that the former

\footnotetext{
1 These include American Stock Exchange (Crack (1995), Ahn, Cao, and Choe (1996), Ronen and Weaver (2001)), Toronto Stock Exchange (Bacidore (1997), Chung, Kryzanowski, and Zhang (1997), Huson, Kim, and Mehrotra (1997), Porter and Weaver (1997) and Ahn, Cao, and Choe (1998)), New York Stock Exchange (Bolley and Whaley (1998), Jones and Lipson (2001), Goldstein and Kavajecz (2000) and Van Ness, Van Ness, and Pruitt (2000)), Stockholm Stock Exchange (Niemeyer and Sandas (1994)), Singapore Stock Exchange (McInish and Lau (1995)), and Australian Stock Exchange (McInish and McCorry (1997)).
} 
uses a single absolute tick size that applies to most stocks, while the latter uses a tick size that is a step function of share price (Angel, 1997). For example, before 1998, the tick size is $¥ 1$ for stocks priced below $¥ 1,000$, $¥ 10$ for stocks priced between $¥ 1,001$ and $¥ 10,000$, and $¥ 100$ for stocks priced between $¥ 10,001$ and $¥ 30,000$. After the tick size change, the tick size becomes $¥ 1$ for stocks priced below $¥ 2,000$, $¥ 5$ for stocks priced between $¥ 2,001$ and $¥ 3,000$, and $¥ 10$ for stocks priced between $¥ 3,001$ and $¥ 30,000$. Therefore, unlike the U.S. equity market where the tick size reduction is uniform, the magnitude of the tick size changes on the Tokyo Stock Exchange depends on the level of the stock prices.

The variable change of the tick size in Tokyo Stock Exchange allows us to conduct a more powerful test of the impact of tick size. First, since the tick size reduction varies across stocks, we could conduct a cross-sectional analysis of its impact on stocks in different price ranges. For example, while the tick size for stocks in the $¥ 1,001 \sim ¥ 2,000$ price range drops by 90 percent (from $¥ 10$ to $¥ 1$ ), the tick size for stocks in the $¥ 2,001 \sim ¥ 3,000$ price range drops only by 50 percent (from $¥ 10$ to $¥ 5$ ). We could therefore examine whether stocks with greater tick size reduction experience a bigger improvement in market quality. Second, unlike the U.S. market, the impact of tick size reduction is not confined to lowpriced stocks. Consider the potential impact of the decimalization in the U.S. market. For a stock in the $\$ 10$ price range, a $\$ 1 / 16$ tick size could be a binding constraint to the liquidity providers in revising quotes. Once the tick size is reduced to 1 cent after the decimalization, the liquidity providers will be able to compete more aggressively in posting quotes so that the bid-ask spread could be lowered below \$1/16. On the other hand, for a stock at the $\$ 50$ price range, a $\$ 1 / 16$ tick size is hardly a binding constraint in the sense that liquidity providers could not lower the bid-ask spread less than $\$ 1 / 16$. Even after the tick size is reduced to 1 cent, this will not change the quote revision behavior of liquidity providers. In the case of the Tokyo Stock Exchange, because the tick sizes form a step function, the tick size for the higher-priced stocks is not necessarily small and could be a binding constraint. For example, for stocks trading at the $¥ 10,001 \sim ¥ 30,000$ price range, the reduction of tick size is 90 percent (from $¥ 100$ to $¥ 10$ ). Consequently,

\footnotetext{
${ }^{2}$ See Harris (1997) for a review of the arguments and evidence on the related literature. Goldstein and Kavajecz
} 
the tick size reduction still has a significant impact on the higher-priced stocks.

Based on a unique and comprehensive tick-by-tick data that became available only recently, we provide a detailed investigation of the impact of minimum tick size reduction on stocks in different price ranges. We investigate several market quality measures, including quoted bid-ask spread, effective bidask spreads and the trading volume before and after the tick size reduction. We also examine how the reduction of bid-ask spread is determined by some characteristics of the firms. For example, we decompose the spreads into transitory and permanent components based on Glosten and Harris (1988), and investigate which component is reduced more. Since the permanent component is a reflection of adverse selection cost while the transitory component partially reflects monopoly rents, we could determine the source of bid-ask spread reduction.

Our evidence shows that there is a significant reduction of both the quoted spread and effective spread after the tick size reduction (around 20-60 percent). The reductions in the spread come mainly from the reduction in transitory component and to a lesser extent from the reduction in permanent component. Since the transitory component is a reflection of the monopoly rents, this suggests that that the source of improved liquidity comes from the decline of monopoly rent enjoyed by liquidity providers. We also observe an increase in the quote revision (relative to the number of trades), suggesting there is more price competition among limit order traders in providing liquidity. Nevertheless, this is not accompanied by an overwhelming increase in trading volume. This suggests that while liquidity providers are revising quotes more aggressively after tick size reduction, they also decrease the depth provided to the market, so that this does not result in a significant increase in trading volume.

The rest of the paper is organized as follows. Section 2 discusses the institutional features of the Tokyo Stock Exchange. Section 3 describes the data sources and the construction of the sample. Section 4 provides the empirical analysis. This is followed by a conclusion in Section 5 .

(2000) also provide a summary of the theoretical models on optimal tick size. 


\section{Institutional Features of Tokyo Stock Exchange}

Stocks on the Tokyo Stock Exchange (TSE) are traded either in the First Section or the Second Section. The First Section handles active stocks while the Second Section is for inactive stocks. As of 1998, 1,233 issues were listed on the First Section while 426 issues were traded on the Second Section. The 150 most-heavily traded First Section stocks were traded on the trading floor under the system called the Floor Order Routing and Execution System (FORES). The remaining First Section stocks and all of the Second Section stocks were traded electronically on the Computer Assisted Order Routing and Execution System (CORES). For stocks traded under CORES, all orders are submitted electronically. For the 150 stocks traded on the exchange floor, orders for 30,000 shares or less are submitted electronically, and orders for more than 30,000 shares will be brought to the exchange floor manually.

The trading on the Tokyo Stock Exchange is order driven; there are no market makers as in London or New York. The saitori plays a central role both in trades transacted through CORES and those transacted manually. Orders, which may be market or limit orders, are entered into the CORES by exchange members via their terminals. However, they are not matched automatically but through the manual intervention of saitori seated in front of screens on which the orders are displayed. The saitori members do not trade on their own account or make markets in the stocks; their function is purely to match the orders received from the other members.

TSE trading takes place in two different trading sessions. The morning session begins at 9:00am and ends at 11:00am, while the afternoon session begins at 12:30pm and ends at 3:00pm. Trade at the beginning of each session is initiated through a single-price auction called the itayose. This is followed by the continuous market called the zaraba. Virtually all trades occurring under the zaraba mechanisms are the result of market orders hitting limit orders or limit orders crossing. Market orders almost never cross in Japan, and occur only if the same member firm represents both sides of the trade. 


\section{Data and samples}

\subsection{Data and sample period}

We obtain the real-time TSE trades and quotes data from Nikkei Economic Electronic Database System (NEEDS) historical tick data. The database is time-stamped to the nearest minute and includes the price information on all quotes and the price and quantity information on all transactions. It also has detailed flags indicating the conditions of each trade and quote. ${ }^{3}$ These flags include the opening/closing trade indicators, buy/sell indicators, and special and warning quote indicators among others. The NEEDS database essentially reflects all the trade and quote information broadcast to TSE members by the TSE. The database is the most detailed and extensive ever among the known data sets on the Japanese stock market.

The sample period spans seven months from January 5, 1998 to July 31, 1998. straddling April 13, 1998 when TSE instituted the tick rule change. The seven-month sample period is divided into two sub-periods of approximately equal length. There are 68 trading days during the pre-event period (January 5 to April 12) and 76 trading days during the post-event period (April 14 to July 31 ).

Since it might take some time for the market to fully absorb the changes in tick size rules, a longer sample period is probably more appropriate to assess the full impact on the market. Furthermore, given that 1998 was a turbulent year for stock markets following the 1997 Asian financial crisis, our analysis is susceptible to changes in liquidity provision in response to general market trends. Therefore, to check the robustness of our main results and to assess the long-term effect of the tick size change, we also examine the data for a four-month period from January 4 to April 30, 1999.

Figure 1 plots the daily level of TOPIX index and the daily turnover of all TSE listed stocks. Both the TOPIX level and turnover decline from late January to June in 1998, and recover slightly in the last two months of the post-event period. Such a market downfall could affect some of the liquidity measures investigated in subsequent analysis. For example, if stock prices are lower in the post-event period, the

\footnotetext{
${ }^{3}$ Quote size information is available from November 1998, which is not included in our sample period.
} 
relative bid-ask spread will become higher even if the dollar bid-ask spread remains the same. Furthermore, since the trading volume is generally lower when the market is on a downward trend, this might reduce the trading interest of liquidity providers, so that fewer investors are submitting quotes. However, since our study is not only to compare the changes in liquidity before and after the tick size reduction, but to compare them across stocks with different tick size reductions, it is not that susceptible to the change in market condition.

\subsection{Test and control samples}

The unusual turbulent market conditions highlight the need for a control sample in order to separately measure the exogenous effect of the tick size change on liquidity variables apart from any endogenous effects on those variables due to the market condition change. In this section, we discuss the construction of the test and control samples.

As we mentioned earlier, the new tick size rule does not uniformly apply to all stocks listed on the TSE. The magnitudes of the tick size reduction also differ significantly among those stocks where the new rule applies. Therefore, we divide the entire sample of the stocks listed on the TSE into several subsamples based on their respective price categories. The test sample consists of groups of stocks whose prices belong to the categories where the new tick rule applies. The control sample consists of groups of stocks in the price categories where the new rule does not apply.

The test samples include groups of stocks priced between $¥ 1,001$ and $¥ 2,000$ (Group 2), between $¥ 2,001$ and $¥ 3,000$ (Group 3), and between $¥ 10,001$ and $¥ 30,000$ (Group 5). The control samples include stocks priced between $¥ 100$ and $¥ 1,001$ (Group 1) and between $¥ 3,001$ and $¥ 10,000$ (Group 4). We pair each test group with a control group in the neighboring price category. Group 1 is the control sample matched for Group 2. ${ }^{4}$ Group 4 serves as the control sample for both Group 3 and Group 5.

\footnotetext{
${ }^{4}$ We also group stocks between $¥ 501$ and $¥ 1,000$ to form an alternative control sample for Group 2 stocks. The empirical results from this alternative control sample are qualitatively the same.
} 
We exclude firms whose prices are extremely low (below $¥ 100$ ) or high (above $¥ 30,000$ ). Stocks below $¥ 100$ are excluded because spreads are sensitive to price levels. Stocks above $¥ 30,000$ are excluded because there are only a few firms in this price category.

For each firm in the test sample or control sample during the pre- or post-event period, a trading day will be considered only if the firm has at least one transaction and the intraday highest and lowest transaction prices are within its respective price category. We include only those firms with at least 35 valid trading days for both the pre- and post-event periods. This leaves 1,161 stocks in Group 1, 156 stocks in Group 2, 40 stocks in Group 3, 63 stocks in Group 4, and 8 stocks in Group 5. The majority of the sample firms have more than 65 and 75 valid trading days, respectively, during the pre- and postevent period. ${ }^{5}$

\section{Empirical results}

\subsection{Quoted bid-ask spread}

We first examine the impact of tick size reduction on the bid-ask spread. According to Harris (1994), the bid-ask spread should be positively related to the minimum tick size. Since the tick size sets the lower bound for the quoted bid-ask spread, liquidity providers cannot improve the spread when it is just one tick. If the minimum tick size is a binding constraint for liquidity providers in posting quotes, a reduction in the tick size will encourage competition among the traders and decrease the spread.

We first examine the quoted bid-ask spread, which is defined as the difference between the lowest ask price and highest bid price of the prevailing quote. When calculating the quoted spread, we only use regular and warning quotes with valid prices. Opening or closing quotes, special quotes, and quotes outside the exchange opening hours are excluded. If the bid-ask spread is greater than a quarter (25 percent) of the bid-ask midpoint, we treat the observation as a coding error and discard it. 
Table 2 summarizes the mean quoted spreads for five groups of stocks surrounding the implementation of the tick size change on the TSE. The quoted spreads are in terms of $¥$ and the figures inside the parentheses are the standard errors. For the two control groups (Group 1 and Group 4) where there is no reduction of the tick size, the percentage changes of the quote spread are 3.96 percent and 5.52 percent, respectively. For the test groups where the minimum tick size is reduced, the decreases in quoted spread are more dramatic. For the stocks in Group $2(¥ 1,001-¥ 2,000)$ where the tick size is reduced from $¥ 10$ to $¥ 1$, the average quoted spread is reduced from $¥ 17.56$ to $¥ 12.66$ (a reduction of 33.6 percent\%). For the stocks in Group 3 ( $¥ 2,001-¥ 3,000$ ) where the tick size is reduced from $¥ 10$ to $¥ 5$, the average quoted spread is reduced from $¥ 22.13$ to $¥ 17.89$ (a reduction of 22.92 percent). For the stocks in Group 5 ( $¥ 10,001-¥ 30,000$ ) where the tick size is reduced from $¥ 100$ to $¥ 10$, the average quoted spread is reduced from $¥ 159.09$ to $¥ 85.26$ (a reduction of 51.09 percent). ${ }^{6}$

We perform the Wilcoxon rank-sum tests for the equality of percentage changes in the quoted spread between the test and control samples, i.e. Group 1 versus Group 2, Group 3 versus Group 4, and Group 4 versus Group 5. The null hypothesis that changes in the quoted spread are equal in each paired samples can be rejected. Overall, consistent with the prediction of Harris (1994), the evidence suggests that the quoted spread drops significantly following the tick size change, indicating that limit-order traders post more aggressive quotes after the constraints on tick size are relaxed.

The evidence from Table 2 also indicates that the decline in quoted spread is positively related to the tick size reduction. For Group 2 and 5 stocks that experience a 90 percent reduction in tick size, their declines in quoted spreads are also greater than Group 3 stocks that experience a 50 percent reduction in tick size. A test of the equality of percentage changes of quote spread across these three groups is rejected at a high significance level.

\footnotetext{
${ }^{5}$ The median numbers of valid trading days during the pre-event period are $67,66,65,68$, and 67 respectively for Groups 1, 2, 3, 4, and 5. The median numbers of valid trading days during the post-event period are 76, 75, 76, 76, and 74 , respectively.
} 
To investigate whether the quoted spread dropped immediately after April 13, 1998 or dropped gradually over time, we examine the time-series behavior of the quoted spreads. We calculate the crosssectional average of quoted spreads on each day for both the test and control samples. Figure 2 plots the time-series patterns for the seven-month period surrounding the tick size change. It shows that the quoted spread dropped abruptly within a few days of the event. The sudden drop is most clear-cut for Group 2 and Group 5 stocks that experienced a 90 percent reduction in tick size. In contrast, the control samples show little evidence of any dramatic movement over time.

\subsection{Effective Bid-Ask Spread}

Using the quoted bid-ask spread as a measure of trading cost assumes that a trade always hit either the bid or ask price. While it is rare, market orders are allowed to cross with each other on the TSE. This happens frequently when there are a lot of market orders arriving in the market, and a broker will cross trades from his own customers' orders, especially for block trades. Therefore, it is possible that market orders cross each other inside the spread. To account for the possibility that transactions sometimes take place inside the quoted spread, we also analyze the effective spread, which is a measure of the actual transaction costs paid by liquidity consumers. The effective spread is defined as $2\left|\mathrm{p}_{\mathrm{t}}-\mathrm{q}_{\mathrm{t}}\right|$, where $\mathrm{p}_{\mathrm{t}}$ is the transaction price and $\mathrm{q}_{\mathrm{t}}$ is the midpoint of the prevailing quote at the time of the trade. Unlike in the U.S. where trades are often reported with a lag, the trades in the TSE are accurately and timely reported immediately following the prevailing bid and ask quotes.

During the pre-event period, 50 percent of the transactions occur at the ask price, 49 percent at the bid price, 0.05 percent within the spread, and 0.07 percent outside the spread. During the post-event period, 45 percent of the transactions occur at the ask price, 55 percent at the bid price, 0.08 percent within the spread, and 0.15 percent outside the spread. As there are only a small percentage of trades

\footnotetext{
${ }^{6}$ As a comparison, studies of tick size reduction on Toronto Stock Exchange typically find a 17-27 percent decline in the quoted spread. Studies of tick size change on AMEX, NYSE, and NASDAQ report a 10-26 percent decline in
} 
inside or outside the spread, it is unlikely that there is a significant difference between the quoted spread measure and effective spread measure. However, if transactions occur more often when spreads are lower, the effective spread could still be significantly lower than the quoted spread.

Table 3 presents the mean effective spreads surrounding the implementation of the tick size change on the TSE. The effective bid-ask spreads are much smaller than the quoted bid-ask spreads (reported in Table 2) for all different groups. Since most of the trades occur at either the bid or ask price, the result that the effective spreads are much lower than the quoted spreads suggests that investors prefer to trade when spreads are narrow. For the three groups where the minimum tick size is reduced, the average effective spreads decline by 40.71 percent, 24.28 percent, and 59.62 percent respectively. Based on the Wilcoxon rank test, the declines in these groups are significantly different from the changes in the control groups. Overall, the evidence indicates there is a decline in actual trading costs paid by investors.

Similar to the results for quoted spreads, the decline in effective spreads is related to the magnitude of tick size reduction. Again, for Group 2 and Group 5 stocks that experience a 90 percent reduction in tick size, the declines in effective spreads are the largest. The null hypothesis that the changes of effective spreads in different groups are equal is rejected at a significant level.

We also examine how the changes of effective spreads vary with the trading activity. According to Harris (1994), the minimum tick size is more likely to be a binding constraint for the more actively traded stocks. Therefore, when the minimum tick size is reduced, it should benefit the actively traded stocks more than the others. To examine this possibility, we divide stocks in each of the three test groups into two sub-samples based on the median daily number of trades in the pre-event period. We then calculate the changes in effective spreads for each sub-sample. Results are presented in Table 4. Consistent with the prediction, the reduction in effective spread is much greater for more actively traded stocks than for less actively traded stocks. The biggest difference is in Group 2, where the reduction in effective spreads is 22.02 percent for the less actively traded stocks and 59.41 percent for the more

the quoted spread depending on the sample. 
actively traded stocks.

\subsection{Permanent and Transitory Component}

Given that there is a reduction of the quoted spread or the effective spread upon the tick size reduction, we would like to know where the transaction cost savings comes from. According to the market microstructure theory, the bid-ask spread consists of order processing costs, inventory costs, and adverse selection costs. Furthermore, Anshuman and Kalay (1998) suggest that the discrete prices create monopoly rents for the liquidity suppliers, so that they could make abnormal profits from processing the orders. Consequently, when the minimum tick size is reduced, this encourages more liquidity providers to submit more competitive quotes so that the profits from monopoly rents decline. We therefore expect that the decline of the quoted spread comes from the reduction of the monopoly rent.

We employ the Glosten and Harris (GH) (1988) model to decompose the bid-ask spread into the permanent and transitory components. The permanent component reflects adverse information costs, and the transitory component reflects order processing costs, inventory costs, and monopoly rents. The GH model on the change of transaction prices follows:

$$
p_{t}-p_{t-1}=-\phi I_{t-1}+(\phi+\theta) I_{t}+\varepsilon_{t}
$$

where $p_{t}$ is the transaction price at time $\mathrm{t}, \mathrm{I}_{\mathrm{t}}$ is the trade indicator at time $\mathrm{t}$ (equal to 1 if the trade is buyer-initiated and equal to -1 if the trade is seller-initiated), $\theta$ is the permanent component, and $\phi$ is the transitory component. The estimation of the model requires a sequence of transaction prices and buy-sell classification. Unlike other market microstructure studies that require either a tick test or the bid-ask test for the classification of trade direction, we do not need such kind of tests. The buy-sell classification is provided by the NEEDS database itself, as it provides for each trade a flag that indicates where it is executed: at the ask, the bid, inside, or outside the spread. 
To identify a valid sequence of trades, we impose the following filters in addition to filters previously used to construct the test and control samples. First, we choose normal trades during the regular trading hours, excluding the opening and closing trades and trades against special quotes. Second, we exclude those transactions within or outside the spreads. A trade that does not satisfy the above conditions will be considered invalid and discarded. Finally, we impose the requirement that there should be at least five valid trades for a given trading day and at least 20 valid trading days for both the pre- and post-event periods. As a result, the number of sample stocks is much smaller after imposing these additional filters.

We use Ordinary Least Squares (OLS) to estimate the $\theta$ and $\phi$ parameters. The estimation is done for each stock and each period (i.e. the pre- and post-event periods). Table 5 reports the crosssectional averages of the two components as well as the proportion of the adverse selection component in the implied spread $(\gamma=2 \theta /(2 \theta+2 \phi))$. All the spread components are expressed as a percentage of prices. Evidence indicates that both the permanent and transitory components decline for the three test groups (Group 2, 3, and 5). Furthermore, the reduction in the transitory component is far greater than the reduction in the adverse selection cost. For example, in Group 5, while the permanent component drops from 0.08 to 0.04 , the transitory component drops from 0.25 to 0.05 . As a result, the proportion of adverse selection cost in the implied spread increases significantly by 14.62 percent, 2.87 percent, and 19.40 percent in the three test groups respectively. When we compare the changes of $\theta, \phi$, and $\gamma$ in the test groups with those in the control groups, the differences are statistically significant.

An interesting question is why the transitory component declined so much. Since we do not expect that the order processing costs and inventory costs to decrease so much within such a short time span, the only possible reason is that the monopoly rents declined. In some ways, the minimum tick size is similar to the price discreteness as it creates monopoly rents for liquidity providers. Consequently, when the tick size is reduced, there is a decline in monopoly rents as reflected in the transitory component. 
To shed light on this possibility, we further investigate the relationship between the reduction of bid-ask spread and the transitory component. For each test group we partition stocks within each test group into two sub-samples based on the GH's estimate of transitory component in the pre-event period $\left(\phi^{P r e}\right)$. If the cross-sectional variation of $\phi^{\text {Pre }}$ comes from the tick size restriction, then upon the minimum tick size reduction, stocks with higher $\phi^{\text {Pre }}$ should experience a larger decrease in bid-ask spread. Table 6 reports the average quoted spread and average effective spread for the two sub-samples partitioned by $\phi^{\text {Pre }}$ in different test groups. For Group 2, there is a significant difference between the spread changes in the low $\phi^{\text {Pre }}$ and in the high $\phi^{\text {Pre }}$ group. For example, the average effective spread decreases by 38.32 percent in the low $\phi^{\text {Pre }}$ group and by 56.55 percent in the high $\phi^{\text {Pre }}$ group. However, for Group 3 and Group 5, we do not find a significant difference between the low and high $\phi^{P r e}$ group. This might be because the spread changes are also affected by some other factors. For example, our earlier results show that changes in bid-ask spreads are influenced also by the level of trading activity. We will revisit this issue when we perform the multivariate regression of spread changes on a set of explanatory variables in Section 4.6.

\subsection{The impact of tick size change on trading activity}

The analysis in the previous section suggests that the trading cost as measured by the quoted spread and effective spread decreased in the TSE after the tick size reduction. While this will lower the trading cost for investors who submit market orders executed at the best quoted prices, this will also lower the profits of liquidity providers so that they are unwilling to supply as much liquidity as before. Therefore, a reduction in tick size will not only lower the bid-ask spread, but also lower quoted depth. Using data from NYSE, Goldstein and Kavajecz (2000) document that both spreads and depths decline after the minimum tick size is reduced.

We therefore examine three volume measures: daily number of trades, share volume, and yen volume. Since volume measures are skewed (Ahn, Cao, and Choe (1996, 1998), we measure the change 
based on the difference in natural logarithms of volume. Results are reported in Table 7. The overall evidence is mixed. While the number of trades is higher for the three test groups, only the changes in Group 2 and Group 5 are statistically different from the control groups. On the other hand, the share volume and yen volume decline in Group 2 and 3, and increase slightly in Group 5. Evidence also indicates that the average trade size is smaller after the tick size reduction. Regardless of whether we measure the trade size in terms of share volume or yen volume, it is generally lower and the changes are statistically different from those in the control groups. Overall, there is no conclusive evidence that will indicate the trading volume increases upon minimum tick size reduction.

It is plausible that the three-month sample period following the tick size change is not long enough for investors to adequately evaluate the trading costs and to adjust their trading strategies. Therefore, it may take a longer time to observe the effect on trading volume. We therefore examine the long-term effects using a four-month sample period from January 4 to April 30, 1999. The results, which are not reported here, show that while the trading volume measures in Group 2 and 3 are significantly higher than in the control group, they are not significantly higher in Group 5. Therefore, the long-term evidence is still inconclusive about the effect of tick size on trading volume.

\subsection{Impact of tick size on quote revisions}

Another impact of the tick size reduction is that liquidity suppliers could compete more aggressively. With a smaller tick size, it becomes easier for limit-order traders to step in front of one another in a limit-order market. Chung and Chuwonganant (2001) find evidence consistent with this conjecture. They show that the number of quote revisions that involve changes in the spread increased dramatically after the tick-size is reduced from $\$ 1 / 8$ to $\$ 1 / 16$. To investigate this possibility, we therefore compare the extent of quote revisions before and after minimum tick size reduction. Since the quote revisions could be affected by the intensity of trading activity, we calculate the quote-to-trade ratio by

dividing the number of quotes by the number of trades. We exclude the opening and closing trades and 
the quotes before the opening trade and after the closing trade. Table 8 reports the quote-to-trade ratio before and after the tick size change and the difference between them. Consistent with our prediction, both the mean and median ratios increased substantially after the tick size reduction, especially for Group 2 and Group 5 stocks. For example, the mean ratio increased from 1.76 to 2.47 for Group 2 stocks, and from 2.59 to 3.62 for Group 5 stocks. The increases in the quote-to-trade ratio in the three test groups are significantly higher than for those in the control groups. Overall, the results indicate that the tick size in the pre-event period is a binding constraint for liquidity suppliers in the quote revisions. After the tick size is reduced, they compete more aggressively by revising the quotes more often.

\subsection{Cross-sectional regression analysis}

Overall, the results suggest that the impact of tick size reduction on spreads differs across stocks. To better understand the determinants of the reduction in quoted and effective spreads, we follow Harris (1994) in estimating cross-sectional regressions to see what variables explain the changes of spread. The regression model is as follows:

$$
\begin{aligned}
\% \Delta \text { Spread }_{i}=\alpha_{0} & +\alpha_{1}\left(\% \Delta \text { Tick }_{i}\right)+\alpha_{2}\left(\% \Delta \text { Tick }_{i} * \text { Logprice }_{i}^{\text {Pre }}\right)+ \\
& +\alpha_{3}\left(\% \Delta \text { Tick }_{i} * \text { LogNumtrade }_{i}^{\text {Pre }}\right)+\alpha_{4}\left(\% \Delta \text { Tick }_{i} * \phi_{i} \text { Pre }^{2}\right)+\varepsilon_{t}
\end{aligned}
$$

where $\% \Delta$ Spread $_{i}$ is the percentage change in the effective (quoted) spread of stock $i$ after the minimum tick size reduction, $\% \Delta$ Tick $_{i}$ is the percentage change in the tick size that is applicable to stock i, Logprice ${ }_{i}^{\text {Pre }}$ is the natural log of average stock price of stock $\mathrm{i}$ in the preevent stock period, LogNumtrade ${ }_{i}^{\text {Pre }}$ is the natural log of the average number of trades of stock i in the pre-event stock period, and $\phi_{i}^{\text {Pre }}$ is the size of transitory component of stock i (as estimated in Table 5) in the pre-event period. Unlike Harris (1994), we introduce explicitly the variable $\% \Delta T_{i c k}$ as the 
explanatory variable because the tick size reduction varies for several stock price categories. When we allow the variable $\% \Delta$ Tick $_{i}$ to interact with the other variables like Logprice $_{i}^{\text {Pre }}$,

$\operatorname{LogNumtrade}{ }_{i}^{\text {Pre }}$, and $\phi_{i}^{\text {Pre }}$, we are therefore testing whether these variables could explain the crosssectional variations of spreads for each tick size category.

Table 9 summarizes the estimation results. Since the regressions use only those stocks that are affected by the tick size change (i.e. Group 2, 3, and 5 stocks only), there are only a total of 171 observations. The evidence for quoted and effective spreads is similar. First, $\% \Delta$ Spread $_{i}$ is positively related to $\% \Delta T_{i c k}$, suggesting that stocks with larger tick size reduction will also experience larger spread declines. Second, we do not find that the spread changes are significantly related to the interaction term involving Logprice ${ }_{i}^{\text {Pre }}$. The result is different from Harris (1994) who finds that the stock price level could explain variation of bid-ask spread. An explanation is that since the change of tick size varies across different stock price categories, the level of stock price is therefore not as critical, so that its impact on spread changes becomes trivial. Third, the spread changes are negatively and significantly related to the interaction term involving $\operatorname{LogNumtrade}_{i}^{\mathrm{Pr} e}$, confirming the earlier results that the spreads decline more for more actively traded stocks. Finally, the spread changes are negatively and significantly related to the interaction term involving the transitory component $\phi_{i}^{\text {Pre }}$. As we discussed earlier, the transitory component $\phi_{i}^{\text {Pre }}$ is a reflection of the monopoly rent in the pre-event period. Our results therefore confirm that the tick size reduction will have a higher impact on bid-ask spreads when the liquidity providers enjoy monopoly rents initially. 


\section{Conclusions}

This paper examines the impact of the change in minimum tick size in the TSE that became effective on April 13, 1998. The TSE is one of the largest limit order markets using a tick size that is a step function of share price. The reduction in tick size therefore depends on price ranges. This offers a more powerful test of the impact of tick size reduction as we could conduct a cross-sectional analysis of its impact on stocks of different tick size categories.

Consistent with studies for other markets, we find that both the quoted spread and effective spread decrease significantly after the tick size reduction (around 20-60 percent\%). While we observe that liquidity providers are more active in posting quotes, there is no significant increase in trading volume. The evidence suggests that the competition among liquidity providers does not necessarily result in a surge in trading activity. Finally, the cross-sectional regression shows that the bid-ask spreads decline more if the stocks experience larger tick size reduction, are more actively traded, and have larger monopoly rents in the pre-event period.

Overall, our evidence shows that the minimum tick size creates monopoly rents for liquidity providers. For example, for the 156 stocks in the $¥ 1001$ - $¥ 2000$ price range, the effective spread is reduced from $¥ 13.48$ to $¥ 8.59$ - a decline of more than 40 percent, and a large portion of the reduction might come from the monopoly rent reduction. Future studies on bid-ask spreads should always consider the monopoly rent component, especially when the tick size is relatively large and becomes a binding constraint to liquidity providers in reducing the bid-ask spreads. 


\section{References}

Ahn, H. J., C. Q. Cao, and H. Choe, 1996, Tick size, spread and volume, Journal of Financial Intermediation 5, 2-22.

Ahn, H. J., C. Q. Cao, and H. Choe, 1998, Decimalization and competition among stock markets:

Evidence from the Toronto Stock Exchange cross-listed securities, Journal of Financial Markets 1, 5187.

Angel, J., 1997, Tick size, share price, and stock splits, Journal of Finance 52, 655-681.

Anshuman, V, and A. Kalay, 1998, Market making rents under discrete prices, Review of Financial Studies 11, 81-109.

Bacidore, J., 1997, The impact of decimalization on market quality: An empirical investigation of the Toronto Stock Exchange, Journal of Financial Intermediation 6, 92-120.

Bessembinder, H., 1998, Endogenous changes in the minimum tick: An analysis of NASDAQ securities trading near ten dollars, Working Paper, Arizona State University.

Bollen, N., and R. Whaley, 1998, Are "teenies" better? Journal of Portfolio Management 25, 10-24.

Chan, K.C., and C. Y. Hwang, 2000, The impact of tick size on the quality of a pure order-driven market: Evidence from the Stock Exchange of Hong Kong, Working paper, Hong Kong University of Science \& Technology.

Chung, R., L. Kryzanowski, and H. Zhang, 1997, Decimalization's winners and losers, Canadian Investment Review, Winter 96/97, 35-39.

Chung, K., and C. Chuwonganant, 2001, Tick size and quote revisions on the NYSE, Working paper, State University of New York at Buffalo.

Crack, T., 1995, Tinkering with ticks: Choosing minimum price variation for U.S. equity markets, Working Paper, Indiana University.

Glosten, L., and L. Harris, 1988, Estimating the components of the bid-ask spread, Journal of Financial Economics 21, 123-142.

Goldsein, M., and K. Kavajecz, 2000, Eighths, sixteenths, and market depth: Changes in tick size and liquidity provision on the NYSE, Journal of Financial Economics 56, 125-149.

Harris, L., 1994, Minimum price variations, discrete bid-ask spreads, and quotation sizes, Review of Financial Studies 7, 149-178.

Harris, L., 1996, Does a large minimum price variation encourage order exposure? Working Paper, University of Southern California.

Harris, L., 1997, Decimalization: A review of the arguments and evidence, Working Paper, University of Southern California. 
Huang, R., and H. Stoll, 1996, Dealer versus auction markets: A paired comparison of execution costs on NASDAQ and the NYSE, Journal of Financial Economics 41, 313-357.

Huson, M, Y. Kim, and V. Mehrotra, 1997, Decimal quotes, market quality, and competition for order flow: Evidence from the Toronto Stock Exchange, Working Paper, University of Alberta.

Jones, C., and M. Lipson, 2001, Sixteenths: Direct evidence on institution trading costs, Journal of Financial Economics 59, 253-278.

McInish, T., and S. T. Lau, 1995, Reducing tick size on the Stock Exchange of Singapore, Pacific Basin Finance Journal 3, 485-496.

McInish, T., and M. McCorry, 1997, Reducing tick size on the Australian Stock Exchange, Working Paper, University of Memphis.

Niemeyer, J., and P. Sandas, 1994, Tick size, market liquidity and trading volume: Evidence from the Stockholm Stock Exchange, Working Paper, Stockholm School of Economics.

Porter, D., and D. Weaver, 1997, Decimalization and market quality, Financial Management 26, 5-26.

Ronen, T., and D. Weaver, 2001, Teenies' anyone: The case of American Stock Exchange, Journal of Financial Markets 4, 231-260.

Van Ness, B., R. Van Ness, and S. Pruitt, 2000, The impact of the reduction in tick increments in major U.S. markets on spreads, depth, and volatility, Review of Quantitative Finance and Accounting 15, 153169. 
Table 1 Tick Size Rule Changes in Tokyo Stock Exchange on April 13, 1998

The minimum price variations (tick sizes) for different price ranges are presented before (pre) and after (post) April 13, 1998, the day on which the new tick size rule became effective on the TSE.

\begin{tabular}{lrc}
\hline & \multicolumn{2}{c}{ Tick Size (¥) } \\
\cline { 2 - 3 } Price Range $¥ ¥)$ & Pre & Post \\
\hline $1 \sim 1,000$ & 1 & 1 \\
$1,001 \sim 2,000$ & 10 & 1 \\
$2,001 \sim 3,000$ & 10 & 5 \\
$3,001 \sim 10,000$ & 10 & 10 \\
$10,001 \sim 30,000$ & 100 & 10 \\
$30,001 \sim 50,000$ & 100 & 50 \\
$50,001 \sim 100,000$ & 100 & 100 \\
$100,001 \sim 1,000,000$ & 1,000 & 1,000 \\
$1,000,001 \sim$ & 10,000 & 10,000 \\
\hline
\end{tabular}




\section{Table 2 The Quoted Spread Before and After TSE Tick Size Changes}

The quoted bid-ask spread and percentage change in the quoted bid-ask spread are calculated for the threemonth periods before (pre) and after (post) April 13, 1998, the day on which the new tick size rule became effective on the TSE. The quoted spread is defined as the difference between the lowest quoted ask price and highest quoted bid price. $P$-values from the Wilcoxon rank-sum test for the equality in percentage changes in the quoted spreads between the paired samples (Group 1 vs. Group 2, Group 3 vs. Group 4, and Group 4 vs. Group 5) are reported. $P$-values are also reported for testing the equality in percentage changes in the quoted spreads between different price categories affected by the tick rule change. * and ** indicate statistical significance at the 5 and 1 percent levels respectively based on the t-test. ${ }^{+}$and ${ }^{++}$indicate statistical significance at the 5 and 1 percent levels respectively based on the Wilcoxon test.

\begin{tabular}{|c|c|c|c|}
\hline & Pre & Post & $\%$ Change \\
\hline \multicolumn{4}{|c|}{ A. Group $1(¥ 101 \sim ¥ 1,000 ; \mathrm{N}=1161)$} \\
\hline Mean & 5.41 & 5.64 & $3.96^{* *}$ \\
\hline (s.e.) & $(0.07)$ & $(0.08)$ & $(0.52)$ \\
\hline Median & 5.29 & 5.42 & $1.91^{++}$ \\
\hline \multicolumn{4}{|c|}{ B. Group $2(¥ 1,001 \sim ¥ 2,000 ; N=156)$} \\
\hline Mean & 17.56 & 12.66 & $-33.60 * *$ \\
\hline (s.e.) & $(0.48)$ & $(0.60)$ & $(1.96)$ \\
\hline Median & 16.09 & 11.20 & $-34.89^{++}$ \\
\hline \multicolumn{4}{|c|}{ C. Group $3(¥ 2,001 \sim ¥ 3,000 ; \mathrm{N}=40)$} \\
\hline Mean & 22.13 & 17.89 & $-22.92 * *$ \\
\hline (s.e.) & $(1.20)$ & $(1.42)$ & $(2.61)$ \\
\hline Median & 22.16 & 17.32 & $-24.76^{++}$ \\
\hline \multicolumn{4}{|c|}{ D. Group $4(¥ 3,001 \sim ¥ 10,000 ; \mathrm{N}=63)$} \\
\hline Mean & 35.28 & 33.40 & $-5.52 * *$ \\
\hline (s.e.) & $(2.76)$ & $(2.76)$ & $(1.65)$ \\
\hline Median & 28.48 & 25.70 & $-5.52^{++}$ \\
\hline \multicolumn{4}{|c|}{ E. Group $5(¥ 10,001 \sim ¥ 30,000 ; N=8)$} \\
\hline Mean & 159.09 & 85.26 & $-51.09 * *$ \\
\hline (s.e.) & (17.69) & (18.95) & (8.19) \\
\hline Median & 156.51 & 92.13 & $-46.17^{++}$ \\
\hline
\end{tabular}

$P$-values from the Wilcoxon rank-sum test for equality in percentage changes in the quoted spread between each price group affected by the tick rule change and its control group

\begin{tabular}{|c|c|c|}
\hline Group 1 vs. Group 2 & Group 3 vs. Group 4 & Group 4 vs. Group 5 \\
\hline 0.000 & 0.000 & 0.000 \\
\hline \multicolumn{3}{|c|}{$\begin{array}{l}P \text {-values from the Wilcoxon rank-sum test for equality in percentage changes in the quoted spread } \\
\text { between different price groups affected by the tick rule change }\end{array}$} \\
\hline Group 2 vs. Group 3 & Group 3 vs. Group 5 & Group 2 vs. Group 5 \\
\hline 0.011 & 0.005 & 0.072 \\
\hline
\end{tabular}




\section{Table 3 The Effective Spread Before and After TSE Tick Size Changes}

The effective spread and percentage change in the effective spread are calculated for the three-month periods before (pre) and after (post) April 13, 1998, the day on which the new tick size rule became effective on the TSE. The effective spread is defined as $2\left|p_{t}-q_{t}\right|$, where $p_{t}$ is the transaction price and $\mathrm{q}_{\mathrm{t}}$ is the midpoint of the prevailing quote at the time of the trade. $P$-values from the Wilcoxon rank-sum test for the equality in percentage changes in the effective spreads between the paired samples (Group 1 vs. Group 2, Group 3 vs. Group 4, and Group 4 vs. Group 5) are reported. $P$-values are also reported for testing the equality in percentage changes in the effective spreads between different price categories affected by the tick rule change. ${ }^{*}$ and $* *$ indicate statistical significance at the 5 and 1 percent levels respectively based on the t-test. ${ }^{+}$and ${ }^{++}$indicate statistical significance at the 5 and 1 percent levels respectively based on the Wilcoxon test.

\begin{tabular}{|c|c|c|c|}
\hline & Pre & Post & $\%$ Change \\
\hline \multicolumn{4}{|c|}{ A. Group $1(¥ 101 \sim ¥ 1,000 ; \mathrm{N}=1161)$} \\
\hline Mean & 3.58 & 3.82 & $6.54 * *$ \\
\hline (s.e.) & $(0.05)$ & $(0.05)$ & $(0.54)$ \\
\hline Median & 3.43 & 3.62 & $4.05^{++}$ \\
\hline \multicolumn{4}{|c|}{ B. Group $2(¥ 1,001 \sim ¥ 2,000 ; N=156)$} \\
\hline Mean & 13.48 & 8.59 & $-40.71 * *$ \\
\hline (s.e.) & $(0.26)$ & $(0.41)$ & $(2.11)$ \\
\hline Median & 12.75 & 7.88 & $-39.37^{++}$ \\
\hline \multicolumn{4}{|c|}{ C. Group $3(¥ 2,001 \sim ¥ 3,000 ; \mathrm{N}=40)$} \\
\hline Mean & 16.28 & 12.96 & $-24.28 * *$ \\
\hline (s.e.) & $(0.77)$ & $(1.06)$ & $(3.05)$ \\
\hline Median & 14.88 & 11.43 & $-27.74^{++}$ \\
\hline \multicolumn{4}{|c|}{ D. Group $4(¥ 3,001 \sim ¥ 10,000 ; N=63)$} \\
\hline Mean & 24.57 & 24.31 & -1.88 \\
\hline (s.e.) & $(1.91)$ & $(2.04)$ & $(2.05)$ \\
\hline Median & 19.45 & 17.95 & $-4.26^{+}$ \\
\hline \multicolumn{4}{|c|}{ E. Group $5(¥ 10,001 \sim ¥ 30,000 ; N=8)$} \\
\hline Mean & 118.33 & 50.17 & $-59.62 * *$ \\
\hline (s.e.) & $(5.67)$ & (10.35) & (7.18) \\
\hline Median & 117.85 & 51.58 & $-55.97^{++}$ \\
\hline
\end{tabular}

$P$-values from the Wilcoxon rank-sum test for equality in percentage changes in the effective spread between each price group affected by the tick rule change and its control group

\begin{tabular}{cccc}
\hline Group 1 vs. Group 2 & Group 3 vs. Group 4 & Group 4 vs. Group 5 \\
& 0.000 & 0.000 & 0.000 \\
\hline
\end{tabular}

$P$-values from the Wilcoxon rank-sum test for equality in percentage changes in the effective spread between different price groups affected by the tick rule change

\begin{tabular}{cccc}
\hline Group 2 vs. Group 3 & Group 3 vs. Group 5 & & Group 2 vs. Group 5 \\
& 0.000 & 0.000 & 0.052 \\
\hline
\end{tabular}




\section{Table 4 Relationship Between Effective Spread Changes and Trading Activity}

The effective spread and percentage change in the effective spread are calculated for the three-month periods before (pre) and after (post) April 13, 1998, the day on which the new tick size rule became effective on the TSE. The effective spread is defined as $2\left|p_{t}-q_{t}\right|$, where $p_{t}$ is the transaction price and $q_{t}$ is the midpoint of the prevailing quote at the time of the trade. The stocks in each price group are split into two sub-samples based on the median number of transactions per day in the pre-event period. $P$-values from the Wilcoxon ranksum test for the equality in percentage changes in the effective spreads between the paired sub-samples in each price category (low vs. high trading activity groups) are reported in the last column. * and ** indicate statistical significance at the 5 and 1 percent levels respectively based on the t-test. ${ }^{+}$and ${ }^{++}$indicate statistical significance at the 5 and 1 percent levels respectively based on the Wilcoxon test.

\begin{tabular}{|c|c|c|c|c|c|c|c|}
\hline & \multicolumn{3}{|c|}{ No. of Trades $<21.3(\mathrm{~N}=78)$} & \multicolumn{3}{|c|}{ No. of Trades $\geq 21.3(\mathrm{~N}=78)$} & \multirow{2}{*}{$\begin{array}{c}\text { Wilcoxon } p \text {-value } \\
\text { for no difference in } \\
\% \text { changes }\end{array}$} \\
\hline & Pre & post & \%change & pre & Post & $\%$ change & \\
\hline Mean & 15.95 & 12.52 & $-22.02 * *$ & 11.02 & 4.65 & $-59.41 * *$ & 0.000 \\
\hline (s.e.) & $(0.32)$ & $(0.43)$ & $(2.08)$ & $(0.13)$ & $(0.31)$ & $(2.11)$ & \\
\hline Median & 15.7 & 12.19 & $-22.64^{++}$ & 10.52 & 4.25 & $-60.49^{++}$ & \\
\hline \multicolumn{8}{|c|}{ B. Group $3(¥ 2,001 \sim ¥ 3,000)$} \\
\hline & \multicolumn{3}{|c|}{ No. of Trades $<30.8(\mathrm{~N}=20)$} & \multicolumn{3}{|c|}{ No. of Trades $\geq 30.8(\mathrm{~N}=20)$} & \\
\hline Mean & 19.61 & 17.24 & $-13.91 * *$ & 12.95 & 8.68 & $-34.66^{* *}$ & 0.000 \\
\hline (s.e.) & $(0.98)$ & $(1.47)$ & $(4.30)$ & $(0.54)$ & $(0.71)$ & $(2.91)$ & \\
\hline Median & 19.38 & 16.04 & $-18.36^{++}$ & 12.66 & 7.76 & $-36.86^{++}$ & \\
\hline \multicolumn{8}{|c|}{ C. Group $5(¥ 10,001 \sim ¥ 30,000)$} \\
\hline & \multicolumn{3}{|c|}{ No. of Trades $<19.3(\mathrm{~N}=4)$} & \multicolumn{3}{|c|}{ No. of Trades $\geq 19.3(\mathrm{~N}=4)$} & \\
\hline Mean & 128.35 & 73.75 & $-42.87 * *$ & 108.31 & 26.59 & $-76.38^{* *}$ & 0.030 \\
\hline (s.e.) & $(7.06)$ & $(7.76)$ & $(4.13)$ & $(5.77)$ & $(8.30)$ & $(6.03)$ & \\
\hline Median & 129.06 & 76.01 & -44.01 & 103.98 & 22.57 & -78.35 & \\
\hline
\end{tabular}




\section{Table 5 Bid-Ask Spread Components Before and After TSE Minimum Tick Size Changes}

The cross-sectional means of the adverse selection cost component of the spread $(\theta)$, the order handling cost component of the spread $(\phi)$, and the percentage proportion of the adverse selection cost in the implied spread $(\gamma=2 \theta / 2(\theta+\phi))$ are estimated using the Glosten and Harris (1988) model for the threemonth periods before (pre) and after (post) April 13, 1998, the day on which the new tick size rule became effective on the TSE. The spread components, $\theta$ and $\phi$, are expressed in percentage of the average stock price during the period. Reported in the last column are the $p$-values from the Wilcoxon rank-sum test for the equality in differences in the estimates before and after the event date between each price group affected by the tick rule change and the respective control group (Group 1 vs. Group 2, Group 3 vs. Group 4, and Group 4 vs. Group 5). * and ** indicate statistical significance at the 5 and 1 percent levels respectively based on the t-test.

\begin{tabular}{|c|c|c|c|c|}
\hline & Pre & Post & $\begin{array}{c}\text { Difference } \\
\text { (After - Before) }\end{array}$ & $\begin{array}{l}\text { Wilcoxon } p \text {-value for } \\
\text { paired sample test } \\
\text { (vs. control group) }\end{array}$ \\
\hline \multicolumn{5}{|c|}{ A. Group 1 ( $¥ 101 \sim ¥ 1,000 ; N=773)$} \\
\hline$\theta$ & 0.14 & 0.13 & $-0.01 * *$ & - \\
\hline$\phi$ & 0.16 & 0.17 & $0.01 * *$ & - \\
\hline$\gamma$ & 47.36 & 44.20 & $-3.16^{* *}$ & - \\
\hline \multicolumn{5}{|c|}{ B. Group $2(¥ 1,001 \sim ¥ 2,000 ; \mathrm{N}=127)$} \\
\hline$\theta$ & 0.10 & 0.07 & $-0.04 * *$ & 0.000 \\
\hline$\phi$ & 0.23 & 0.08 & $-0.15^{* *}$ & 0.000 \\
\hline$\gamma$ & 30.87 & 45.49 & $14.62 * *$ & 0.000 \\
\hline \multicolumn{5}{|c|}{ C. Group 3 ( $¥ 2,001 \sim ¥ 3,000 ; N=38)$} \\
\hline$\theta$ & 0.09 & 0.07 & $-0.03 * *$ & 0.000 \\
\hline$\phi$ & 0.15 & 0.09 & $-0.05^{* *}$ & 0.000 \\
\hline$\gamma$ & 38.15 & 41.02 & $2.87 * *$ & 0.000 \\
\hline \multicolumn{5}{|c|}{ D. Group $4(¥ 3,001 \sim ¥ 10,000 ; \mathrm{N}=51)$} \\
\hline$\theta$ & 0.07 & 0.06 & $-0.01 * *$ & - \\
\hline$\phi$ & 0.09 & 0.09 & 0.00 & - \\
\hline$\gamma$ & 43.58 & 40.34 & $-3.24 * *$ & - \\
\hline \multicolumn{5}{|c|}{ E. Group $5(¥ 10,001 \sim ¥ 30,000 ; N=6)$} \\
\hline$\theta$ & 0.08 & 0.04 & $-0.04 *$ & 0.036 \\
\hline$\phi$ & 0.25 & 0.05 & -0.20 & 0.000 \\
\hline$\gamma$ & 25.60 & 44.99 & $19.40^{*}$ & 0.000 \\
\hline
\end{tabular}




\section{Table 6 Relationship Between Spread Changes and the Transitory Spread Component in the Pre-Event Period $\left(\phi^{\text {Pre }}\right)$}

The quoted as well as effective spreads and their percentage changes are calculated for the three-month periods before (pre) and after (post) April 13, 1998, the day on which the new tick size rule became effective on the TSE. The quoted spread is defined as the difference between the lowest quoted ask price and the highest quoted bid price. The effective spread is defined as $2\left|p_{t}-q_{t}\right|$, where $p_{t}$ is the transaction price and $q_{t}$ is the midpoint of the prevailing quote at the time of the trade. The stocks within each price group are split into two sub-samples based on the cross-sectional median of the percentage transitory component of the spread in the pre-event period. The transitory component, ( $\phi^{\text {Pre }}$ ), is estimated using Glosten and Harris (1988) model. The $p$-values from the Wilcoxon rank-sum test for the equality in percentage changes in the spreads between the paired subsamples partitioned by the median percentage $\phi$ are reported in the last column. $*$ and $* *$ indicate statistical significance at the 5 and 1 percent levels respectively based on the t-test. ${ }^{+}$and ${ }^{++}$indicate statistical significance at the 5 and 1 percent levels respectively based on the Wilcoxon test.

\begin{tabular}{|c|c|c|c|c|c|c|c|c|}
\hline & & \multicolumn{3}{|c|}{$\phi<0.218 \%(\mathrm{~N}=63)$} & \multicolumn{3}{|c|}{$\phi \geq 0.218 \%(\mathrm{~N}=64)$} & \multirow{2}{*}{$\begin{array}{c}\text { Wilcoxon } p \text {-value } \\
\text { for no difference in } \\
\% \text { changes }\end{array}$} \\
\hline & & pre & Post & $\%$ change & pre & post & \%change & \\
\hline \multirow{2}{*}{$\begin{array}{l}\text { Quoted } \\
\text { Spread }\end{array}$} & Mean & 17.97 & 12.82 & $-30.84^{* *}$ & 13.33 & 7.46 & $-48.33^{* *}$ & 0.000 \\
\hline & Median & 18.66 & 13.40 & $-33.50^{++}$ & 11.81 & 6.16 & $-47.65^{++}$ & \\
\hline \multirow{2}{*}{$\begin{array}{l}\text { Effective } \\
\text { Spread }\end{array}$} & Mean & 13.46 & 8.61 & $-38.32^{* *}$ & 11.40 & 5.27 & $-56.55^{* *}$ & 0.000 \\
\hline & Median & 13.47 & 8.74 & $-38.15^{++}$ & 10.49 & 4.29 & $-59.68^{++}$ & \\
\hline \multicolumn{9}{|c|}{ B. Group $3(¥ 2,001 \sim ¥ 3,000)$} \\
\hline & & \multicolumn{3}{|c|}{$\phi<0.141 \%(\mathrm{~N}=19)$} & \multicolumn{3}{|c|}{$\phi \geq 0.141 \%(\mathrm{~N}=19)$} & \\
\hline \multirow{2}{*}{$\begin{array}{l}\text { Quoted } \\
\text { Spread }\end{array}$} & Mean & 21.82 & 17.99 & $-21.03^{* *}$ & 21.60 & 16.78 & $-26.34^{* *}$ & 0.599 \\
\hline & Median & 21.97 & 17.31 & $-22.54^{++}$ & 20.18 & 15.80 & $-27.17^{++}$ & \\
\hline \multirow{2}{*}{$\begin{array}{l}\text { Effective } \\
\text { Spread }\end{array}$} & Mean & 15.98 & 13.12 & $-22.32^{* *}$ & 16.40 & 12.35 & $-28.29^{* *}$ & 0.827 \\
\hline & Median & 14.59 & 11.17 & $-31.55^{++}$ & 14.95 & 11.54 & $-26.79^{++}$ & \\
\hline \multicolumn{9}{|c|}{ C. Group $5(¥ 10,001 \sim ¥ 30,000)$} \\
\hline & & \multicolumn{3}{|c|}{$\phi<0.221 \%(\mathrm{~N}=3)$} & \multicolumn{3}{|c|}{$\phi \geq 0.221 \%(\mathrm{~N}=3)$} & \\
\hline \multirow{2}{*}{$\begin{array}{l}\text { Quoted } \\
\text { Spread }\end{array}$} & Mean & 104.14 & 27.91 & $-73.90^{*}$ & 117.06 & 47.83 & $-63.15^{*}$ & 0.383 \\
\hline & Median & 101.81 & 18.95 & -81.38 & 107.09 & 27.69 & -74.14 & \\
\hline \multirow{2}{*}{$\begin{array}{l}\text { Effective } \\
\text { Spread }\end{array}$} & Mean & 120.88 & 55.21 & $-55.76^{*}$ & 156.81 & 83.23 & $-49.35^{*}$ & 0.383 \\
\hline & Median & 125.18 & 49.80 & -60.22 & 169.50 & 81.96 & -51.65 & \\
\hline
\end{tabular}




\section{Table 7 Trading Activity Before and After TSE Minimum Tick Size Changes}

The average daily number of trades, share volume, yen volume, and average trade size in number of shares as well as in yen are calculated for the three-month periods before (pre) and after (post) April 13, 1998, the day on which the new tick size rule became effective on the TSE. Also reported are the log-differences in each trading activity variable between the pre and post periods. The $p$-values from the Wilcoxon rank-sum test for the equality in change of each trading activity variable between each price group affected by the tick rule change and the respective control group (Group 1 vs. Group 2, Group 3 vs. Group 4, and Group 4 vs. Group 5) are reported in the last column. $*$ and $* *$ indicate statistical significance at the 5 percent and 1 percent levels respectively based on the t-test.

\begin{tabular}{|c|c|c|c|c|}
\hline & Pre & Post & Log difference & $\begin{array}{l}\text { Wilcoxon } p \text {-value for } \\
\text { paired sample test } \\
\text { (vs. control group) }\end{array}$ \\
\hline \multicolumn{5}{|c|}{ A. Group $1(¥ 101 \sim ¥ 1,000 ; \mathrm{N}=1161)$} \\
\hline No. of Trades & 47 & 41 & $-0.27 * *$ & - \\
\hline Share Volume & 304,622 & 257,110 & $-0.32 * *$ & - \\
\hline Yen Volume & 116,583 & 96,483 & $-0.38 * *$ & - \\
\hline Trade Size in Shares & 3,773 & 3,513 & $-0.07 * *$ & - \\
\hline Trade Size in Yen & 1,492 & 1,324 & $-0.12 * *$ & - \\
\hline \multicolumn{5}{|c|}{ B. Group $2(¥ 1,001 \sim ¥ 2,000 ; \mathrm{N}=156)$} \\
\hline No. of Trades & 47 & 58 & $0.11^{* *}$ & 0.000 \\
\hline Share Volume & 344,832 & 286,414 & $-0.13 * *$ & 0.000 \\
\hline Yen Volume & 492,226 & 393,237 & $-0.11 * *$ & 0.000 \\
\hline Trade Size in Shares & 4,066 & 2,887 & $-0.25 * *$ & 0.000 \\
\hline Trade Size in Yen & 5,698 & 4,096 & $-0.23 * *$ & 0.000 \\
\hline \multicolumn{5}{|c|}{ C. Group $3(¥ 2,001 \sim ¥ 3,000 ; \mathrm{N}=40)$} \\
\hline No. of Trades & 56 & 62 & $0.06^{*}$ & 0.970 \\
\hline Share Volume & 169,560 & 164,049 & -0.05 & 0.396 \\
\hline Yen Volume & 395,661 & 385,563 & -0.02 & 0.692 \\
\hline Trade Size in Shares & 2,186 & 1,903 & $-0.13 * *$ & 0.403 \\
\hline Trade Size in Yen & 5,041 & 4,539 & $-0.09 * *$ & 0.821 \\
\hline \multicolumn{5}{|c|}{ D. Group $4(¥ 3,001 \sim ¥ 10,000 ; \mathrm{N}=63)$} \\
\hline No. of Trades & 74 & 79 & $0.06^{*}$ & - \\
\hline Share Volume & 192,819 & 197,650 & -0.03 & - \\
\hline Yen Volume & 867,814 & 881,379 & -0.01 & - \\
\hline Trade Size in Shares & 1,746 & 1,599 & $-0.12 * *$ & - \\
\hline Trade Size in Yen & 8,003 & 7,388 & $-0.10 * *$ & - \\
\hline \multicolumn{5}{|c|}{ E. Group $5(¥ 10,001 \sim ¥ 30,000 ; N=8)$} \\
\hline No. of Trades & 72 & 106 & $0.22 *$ & 0.076 \\
\hline Share Volume & 137,874 & 145,613 & 0.05 & 0.737 \\
\hline Yen Volume & $1,490,757$ & $1,619,696$ & 0.05 & 0.849 \\
\hline Trade Size in Shares & 946 & 775 & $-0.24^{*}$ & 0.100 \\
\hline Trade Size in Yen & 11,721 & 10,206 & -0.24 & 0.096 \\
\hline
\end{tabular}




\section{Table 8 The Quote-to-Trade Ratio Before and After TSE Minimum Tick Size Changes}

The quote-to-trade ratio (the number of quotes divided by the number of trades) and the change in the quote-to-trade ratios (measured in difference) are calculated for the three-month periods before (pre) and after (post) April 13, 1998, the day on which the new tick size rule became effective on the TSE. The $p$ values from the Wilcoxon rank-sum test for the equality in changes of the quote-to-trade ratio between each price group affected by the tick rule change and the respective control group (Group 1 vs. Group 2, Group 3 vs. Group 4, and Group 4 vs. Group 5) are reported in the last column. * and ** indicate statistical significance at the 5 and 1 percent levels respectively based on the t-test. ${ }^{+}$and ${ }^{++}$indicate statistical significance at the 5 and 1 percent levels respectively based on the Wilcoxon test.

\begin{tabular}{|c|c|c|c|c|}
\hline & Pre & Post & $\begin{array}{c}\text { Difference } \\
(\text { Post - Pre) }\end{array}$ & $\begin{array}{l}\text { Wilcoxon } p \text {-value for } \\
\text { paired sample test } \\
\text { (vs. control group) }\end{array}$ \\
\hline \multicolumn{5}{|c|}{ A. Group $1(¥ 101 \sim ¥ 1,000 ; \mathrm{N}=1161)$} \\
\hline Mean & 2.37 & 2.52 & $0.16^{* *}$ & - \\
\hline (s.e.) & $(0.02)$ & $(0.03)$ & $(0.01)$ & \\
\hline Median & 2.35 & 2.56 & $0.10^{++}$ & \\
\hline \multicolumn{5}{|c|}{ B. Group $2(¥ 1,001 \sim ¥ 2,000 ; N=156)$} \\
\hline Mean & 1.76 & 2.47 & $0.71 * *$ & 0.000 \\
\hline (s.e.) & $(0.06)$ & $(0.07)$ & $(0.03)$ & \\
\hline Median & 1.62 & 2.35 & $0.71^{++}$ & \\
\hline \multicolumn{5}{|c|}{ C. Group $3(¥ 2,001 \sim ¥ 3,000 ; N=40)$} \\
\hline Mean & 1.78 & 2.01 & $0.23 * *$ & 0.000 \\
\hline (s.e.) & $(0.15)$ & $(0.20)$ & $(0.07)$ & \\
\hline Median & 1.65 & 1.84 & $0.11^{++}$ & \\
\hline \multicolumn{5}{|c|}{ D. Group $4(¥ 3,001 \sim ¥ 10,000 ; N=63)$} \\
\hline Mean & 1.94 & 1.90 & -0.04 & - \\
\hline (s.e.) & $(0.13)$ & $(0.16)$ & $(0.07)$ & \\
\hline Median & 1.52 & 1.50 & $-0.03^{+}$ & \\
\hline \multicolumn{5}{|c|}{ E. Group $5(¥ 10,001 \sim ¥ 30,000 ; N=8)$} \\
\hline Mean & 2.59 & 3.62 & $1.03^{*}$ & 0.000 \\
\hline (s.e.) & $(0.85)$ & (1.10) & $(0.36)$ & \\
\hline Median & 1.84 & 2.21 & $0.50^{++}$ & \\
\hline
\end{tabular}




\section{Table 9 Cross-Sectional Regressions of Spread Changes}

The percentage changes in the average quoted and effective spreads are regressed on the percentage change in the tick size, $\% \Delta$ Tick, and its products with each of the following three variables: the natural log of the average stock price, LogPrice ${ }^{P r e}$, the natural log of the daily number of trades, LogNumtrade ${ }^{P r e}$, and the transitory component of the spread estimated in the pre-event period $\left(\phi^{P r e}\right)$. The average stock prices, daily numbers of trades, and the percentage transitory component estimates are calculated from the pre-event period. * and ** indicate statistical significance at the 5 and 1 percent levels respectively based on the t-test.

\begin{tabular}{|c|c|c|}
\hline Independent Variable & $\begin{array}{l}\text { Percentage Change in } \\
\text { Quoted Spread }\end{array}$ & $\begin{array}{l}\text { Percentage Change in } \\
\text { Effective Spread }\end{array}$ \\
\hline Intercept & $\begin{array}{l}-41.41 \\
(-14.15)^{* *}\end{array}$ & $\begin{array}{l}-51.40 \\
(-17.03)^{* *}\end{array}$ \\
\hline$\% \Delta$ Tick & $\begin{array}{l}6.69 \\
(2.83)^{* *}\end{array}$ & $\begin{array}{l}7.48 \\
(3.06)^{* *}\end{array}$ \\
\hline$\% \Delta$ Tick $\times$ LogPrice $e^{\text {Pre }}$ & $\begin{array}{l}-0.52 \\
(-1.75)\end{array}$ & $\begin{array}{l}-0.58 \\
(-1.89)\end{array}$ \\
\hline$\% \Delta$ Tick $\times$ LogNumtrade $e^{\text {Pre }}$ & $\begin{array}{l}-0.41 \\
(-6.63)^{* *}\end{array}$ & $\begin{array}{l}-0.50 \\
(-7.23)^{* *}\end{array}$ \\
\hline$\% \Delta$ Tick $\times \phi^{\text {Pre }}$ & $\begin{array}{l}-4.73 \\
(3.36)^{* *}\end{array}$ & $\begin{array}{l}-5.51 \\
(-3.13)^{* *}\end{array}$ \\
\hline F-value & $24.35^{* *}$ & $31.71 * *$ \\
\hline Adjusted $\mathrm{R}^{2}$ & 0.36 & 0.42 \\
\hline
\end{tabular}




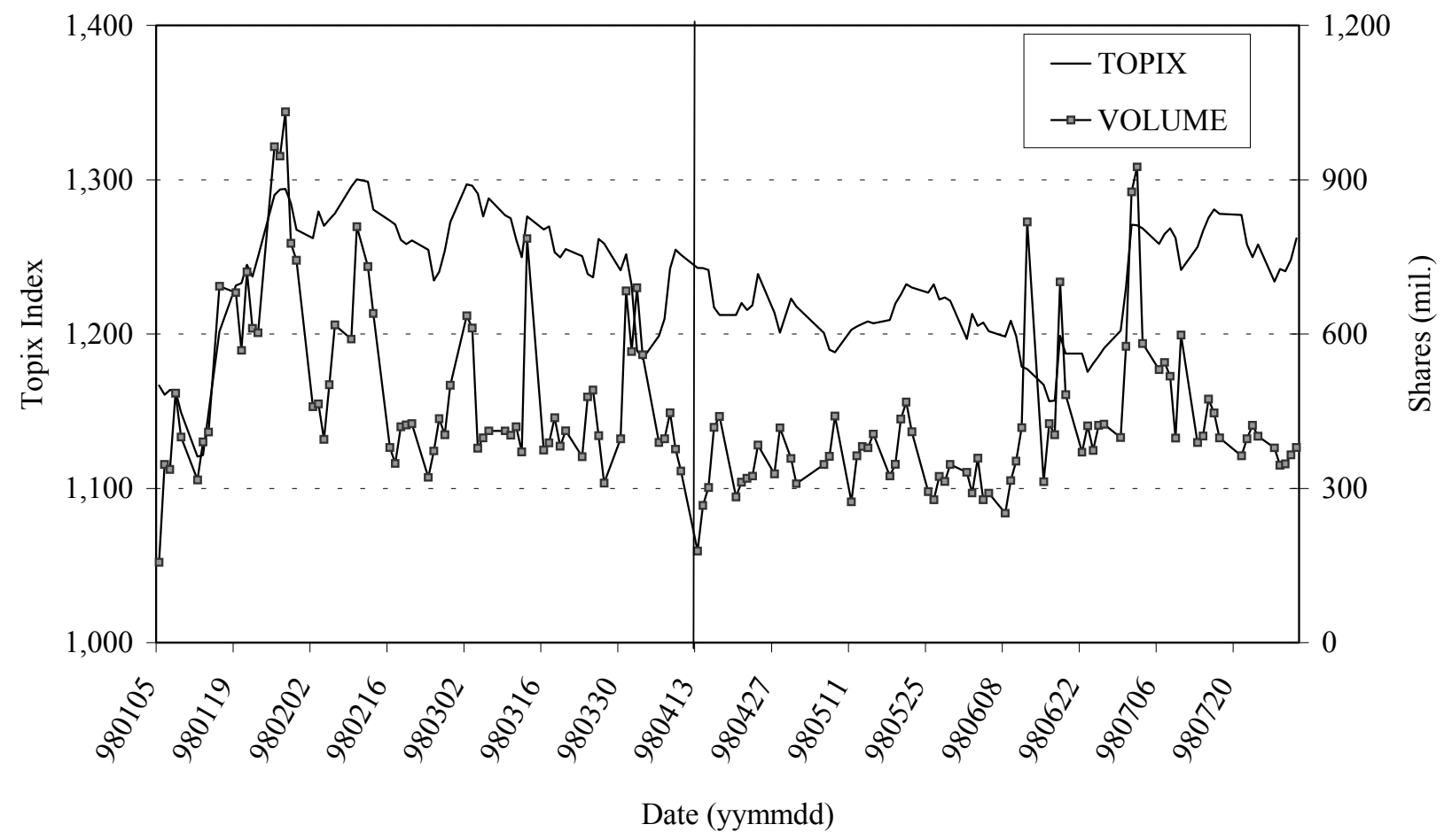

Figure 1. Daily TOPIX Index and Total Turnover on the TSE

The figure plots the daily TOPIX index and total turnover (in million shares) on the TSE over the sevenmonth period from January 5, 1998 to July 31, 1998. The vertical line in the middle indicates April 13, 1998, the date on which the TSE implemented the new tick-size rule. 
A. Group $2(¥ 1,001 \sim ¥ 2,000)$

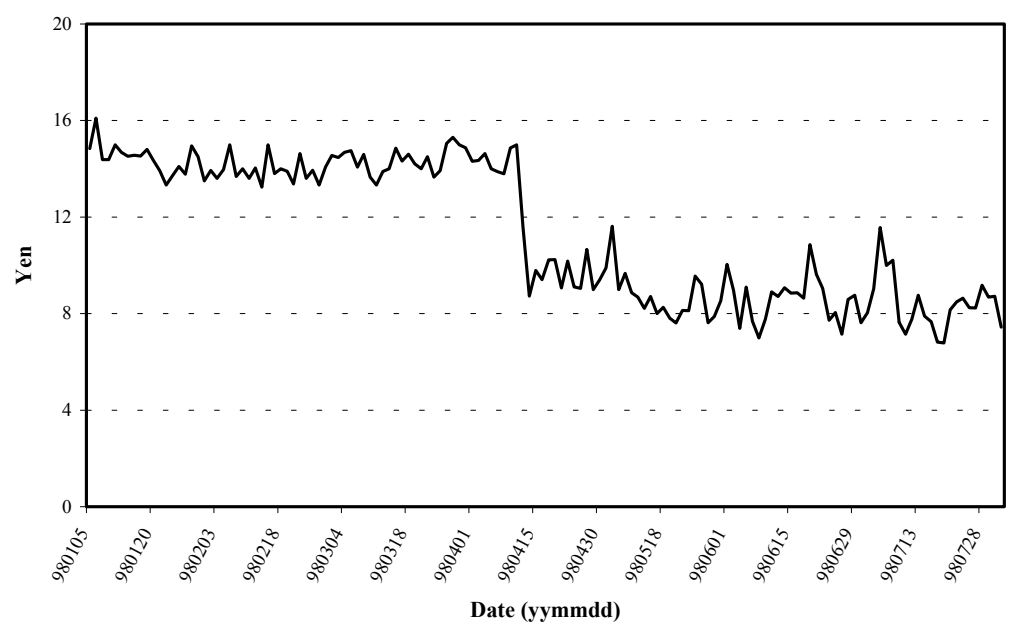

B. Group $3(¥ 2,001 \sim ¥ 3,000)$

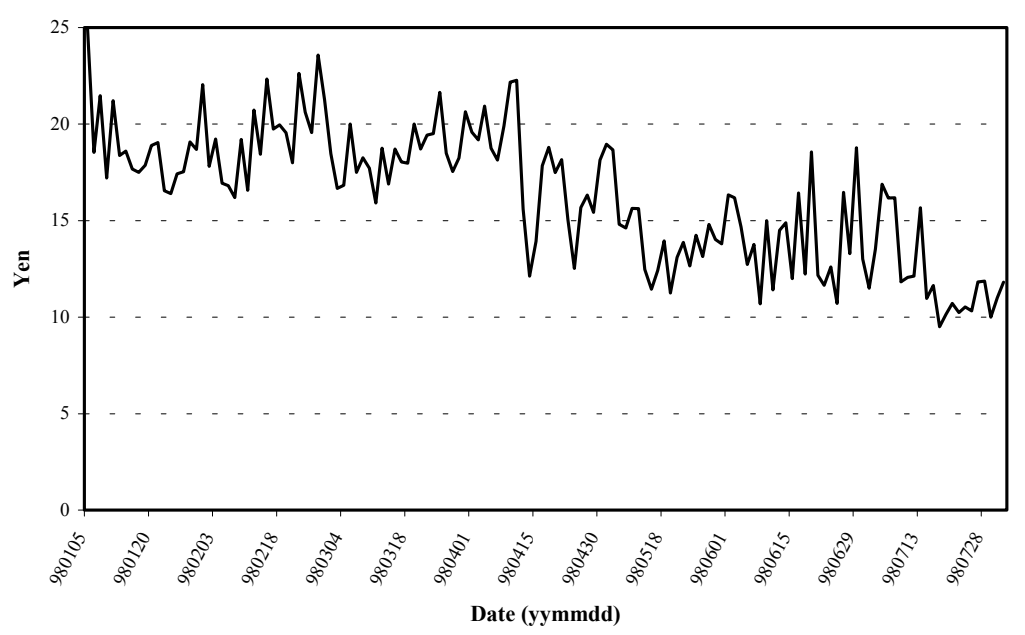

C. Group $5(¥ 10,001 \sim ¥ 30,000)$

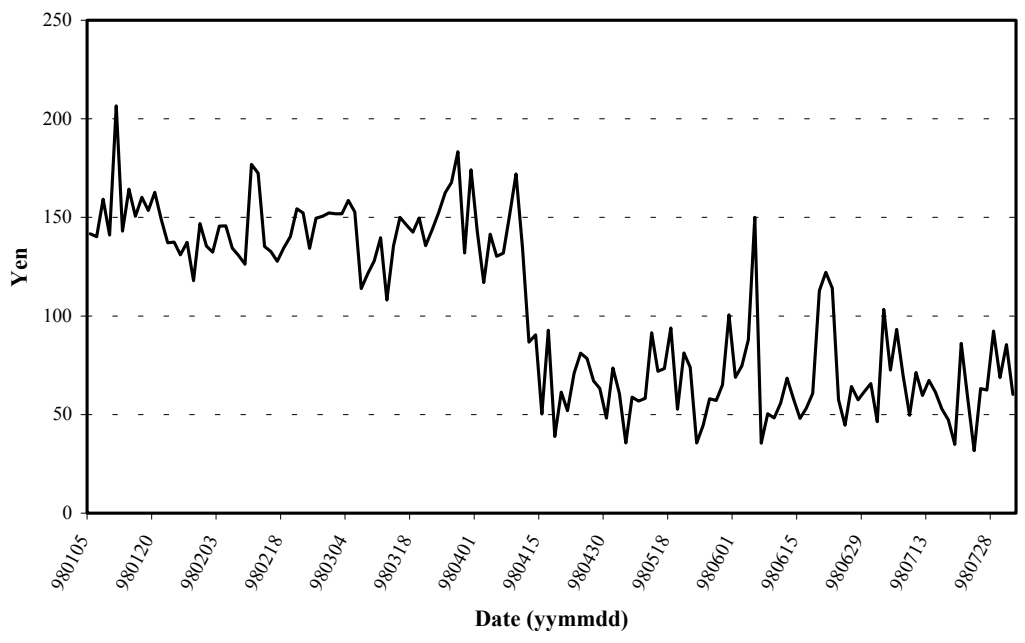

Figure 2. Median Daily Spreads (Test Groups) 
D. Group 1 (¥101 ¥1,000)

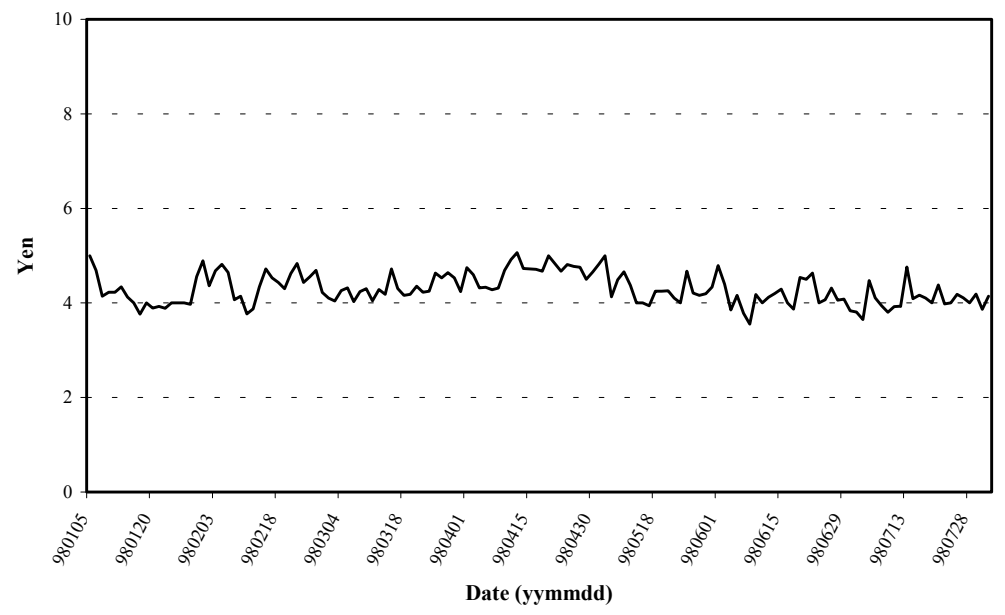

E. Group $4(¥ 3,001 \sim ¥ 10,000)$

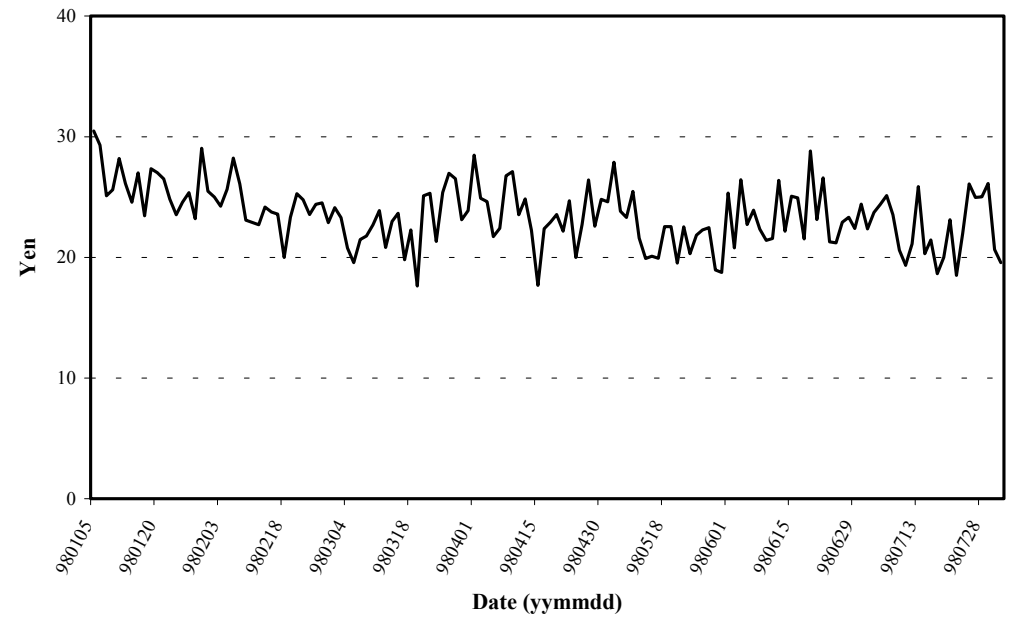

Figure 2. Median Daily Spreads (Control Groups) 